\title{
Essentially Rational Animals
}

\section{Citation}

Boyle, Matthew. Forthcoming. Essentially rational animals. In Rethinking epistemology, ed. Guenther Abel and James Conant. Berlin, Germany: Walter de Grutyer.

\section{Permanent link}

http://nrs.harvard.edu/urn-3:HUL.InstRepos:8641838

\section{Terms of Use}

This article was downloaded from Harvard University's DASH repository, and is made available under the terms and conditions applicable to Other Posted Material, as set forth at http:// nrs.harvard.edu/urn-3:HUL.InstRepos:dash.current.terms-of-use\#LAA

\section{Share Your Story}

The Harvard community has made this article openly available.

Please share how this access benefits you. Submit a story.

Accessibility 
Essentially Rational Animals

Matthew Boyle, Harvard University

—Forthcoming in Rethinking Epistemology, ed. G. Abel and J. Conant-

\begin{abstract}
One may call this whole disposition of the human being's powers whatever one likes: understanding, reason, awareness, etc. It is indifferent to me, so long as one does not assume these terms to name discrete powers or mere increased levels of the animal powers. It is the whole organization of all human powers; the whole domestic economy of his sensing and cognizing, his cognizing and willing nature... The difference is not in levels or the addition of powers, but in a quite different sort of orientation and unfolding of all powers.
\end{abstract}

J. G. Herder, Treatise on the Origin of Languages I, §2 (2002, pp. 82-3)

\title{
1. Introduction
}

1.1 According to a tradition reaching back at least as far as Aristotle, human beings are set apart from other terrestrial creatures by their rationality. Other animals, according to this tradition, are capable of sensation and appetite, but they are not capable of thought, the kind of activity characteristic of the rational part of the soul. Human beings, by contrast, are rational animals, and an understanding of our minds must begin from a recognition of this distinctiveness. For, the tradition holds, the presence of rationality does not just add one more power to the human mind, or increase the scope and efficacy of mental powers already present in nonrational creatures. Rather, rationality transforms all of our principal mental powers, making our minds different in kind from the minds of nonrational animals. ${ }^{1}$

Although the historical roots of this tradition run deep, I think it is fair to say that many contemporary philosophers regard it with suspicion. No one doubts, of course, that there are all sorts of differences between human beings and other animals, but we do not have much use these days for the idea of a single, all-pervading difference. Our philosophy of mind seeks not primarily to characterize the human mind's distinctiveness but to show

\footnotetext{
${ }^{1}$ Aristotle himself would of course speak, not of kinds of mind, but of kinds of soul (psuchē). But our word "psychology" descends from this Aristotelian word, and allowing ourselves the modern term "mind" permits us to describe the Aristotelian position in terms that bring out its bearing on topics of contemporary concern.
} 
how our minds fit into the natural world, and the demand that human mentality be conceived as fundamentally continuous with the mentality of other animals looks to many like just a piece of naturalistic common sense. For whatever we mean by calling our minds "rational," surely this must be compatible with a recognition that the human mind is a species of animal mind, which has arisen through the same sorts of evolutionary processes that also produced the minds we call "nonrational." And the more we learn about the cognitive, behavioral, and neurophysiological similarities between ourselves and other animals, and about the extent to which we "rational" creatures frequently think and choose in ways that systematically deviate from what rational principles would dictate, the more we seem compelled to regard the specialness of our minds as merely a matter of degree, not a difference in kind. ${ }^{2}$ Jerry Fodor expresses this thought with characteristic directness: [T] he whole idea that there are two (or more?) fundamentally different kinds of minds might strike one as unparsimonious... Surely it's reasonable, absent contrary evidence, to suppose the differences between our minds and theirs are largely quantitative. The latter, after all, are widely supposed to have evolved from the former; and, indisputably, our babies turn into us. The gap can't be impassable in either case. (Fodor 2003, p. 16)

1.2 The difficulty facing the Aristotelian position, however, is not merely one of justifying the distinction it draws, but of explaining what this sort of distinction could even amount to. For what could it mean to posit a difference "in kind" between our minds and those of other animals? On a loose understanding of the idea of a difference in kind, we could say that we have two different kinds of thing wherever we have two things which differ in respect of some nonrelational property. No one will deny that a typical human mind differs in kind from (e.g.) a typical chimpanzee mind in this sense, but by the same token, no one will be inclined to make a big deal of it. Of course there are differences between human minds and the minds of other species of animals, but why should these differences be of any more interest than the differences between the minds of chimpanzees and those of orangutans, or

\footnotetext{
2 For a review of continuities between human cognition and the cognition of other primates, see for instance Tomasello and Call 1997. Standard works on nonrational cognitive biases in human judgment and choice include Nisbett and Ross 1980 and Kahneman, Slovic and Tversky 1982.
} 
dolphins? Why, for that matter, should they be of any more interest than the differences between one person's mind and another's? Each of these differences may be of interest to some particular inquiry - to comparative psychology, to "cognitive ethology," to the study of variations in individual cognitive ability, etc. - but none of them seems to merit the sort of absolute interest that the rational/nonrational distinction was traditionally supposed to command.

There are familiar images used to indicate the nature of this special interest. Jonathan Bennett, for instance, begins his book Rationality by offering the following gloss on the idea that human minds differ in kind from those of other creatures:

It is commonly believed... that between a genius and a stupid man there is a smooth slide while between a stupid man and an ape there is a sharp drop, not just in the sense that there are no creatures intellectually half-way between apes and stupid men, but in the sense that there could not be such creatures. Any possible creature whose intellectual level was higher than that of normal apes and lower than that of normal men-so the common belief runs-either would or would not have that special something which puts humans importantly above other animals. (Bennett 1964, p. 4)

This characterization of the idea of a difference in kind is evocative, but in the end, I do not think it clarifies what sort of the difference is at issue. The suggestion that there could be no creatures whose intellects stand half-way between apes and men just amounts to the insistence that the rational-nonrational opposition is exclusive: for any creature, we will say either that it is rational or that it is not. But this might be true although the opposition in question was simply stipulative, an arbitrary line drawn at a certain point on what is in fact a continuum. Thus we might draw an exclusive distinction between persons over six feet tall and persons of six feet or less, calling the former group "tall" and the latter "non-tall"; but although this distinction might be useful for certain purposes, it clearly would not mark a difference in kind in the intended sense. Nor does it seem sufficient to require that the difference be discontinuous. The difference between a steam engine and an internal combustion engine, for instance, presumably involves a sharp break rather than a continuous transition: for what would the relevant continuum be? But this difference, although undoubtedly significant, does not seem to possess whatever sort of necessity and 
inevitability the rational/nonrational contrast is traditionally supposed to have.

1.3 I have been emphasizing these difficulties in order to bring out that the idea of a difference in kind between rational and nonrational minds needs clarification before it can assessed, and that supplying the needed clarification is not a straightforward task. I think this task is often overlooked by both fans and detractors of the distinction. People hostile to the idea that there is a deep distinction here tend to marshal a familiar battery of arguments against it, as Fodor does in the passage quoted earlier, without asking exactly what sort of claim the "difference in kind" thesis is supposed to be. But equally, people sympathetic to the idea often rush to specify what the distinction is, without explaining why the specification they give should count as a fundamental distinction between kinds of mind.

Any attempt to evaluate the thesis that rational minds differ in kind from nonrational ones must, I think, begin by asking what the significance of this thesis is supposed to be. What sort of difference is a difference "in kind" meant to be, and how is the rationalnonrational contrast supposed to amount to that sort of difference? The present essay is a contribution to this preliminary but essential task. I want to understand what sort of distinction writers in the Aristotelian tradition meant to be drawing when they distinguished rational from nonrational minds, and what sort of depth they were claiming for this distinction. I will begin by offering a sketch of the outlook to which the rational/nonrational distinction traditionally belonged, and will suggest that we can only understand the nature and importance of this distinction if we recognize how it is bound up with an attempt to characterize the form of a certain type of substance, one possessing powers of a certain distinctive kind $(\S 2)$. I will go on to argue that a variety of standard objections to the thesis that rational minds differ in kind from nonrational ones rest on a misunderstanding of the character of this thesis through failing to see it against this background $(\S 3)$. The present essay will thus be a contribution to the defense of the rational/nonrational distinction in its classical form; but it will fall far short of being a full account of what rationality amounts to. It should be seen, rather, as a kind of 
prolegomenon: a specification of the framework into which a satisfying account of rationality would have to fit.

\section{The Classical View}

2.1 It is often said that Aristotle defined man as a rational animal. ${ }^{3}$ What is less frequently discussed is the outlook to which the project of "defining man" belonged: What is a definition supposed to be, and how should we understand the import of the terms that appear in one? My aim in this section is to sketch what I will call the "Classical View" of these matters, in order to bring out its bearing on our question about what it means to claim that a rational creature has a different kind of mind than a nonrational one.

By the Classical View, I mean the view to be found in Aristotle and in that strain of medieval Aristotelianism of which Thomas Aquinas is the greatest expositor. Of course the interpretation of Aristotle is highly contested, as is the question of the relation of his ideas to the views of later thinkers inspired by him, so it hardly needs emphasizing that what I am presenting is only $a$ reading of certain well-known Aristotelian and post-Aristotelian texts. I will present this reading more or less dogmatically, without addressing alternative interpretations or scrutinizing texts in detail. My excuse for this procedure is that my interest is not finally historical anyway: I am interested in bringing out a point of view that has a plausibility in its own right and a bearing on contemporary debates.

I want to explore three key ideas belonging to the Classical View: first, the idea that "rational animal" belongs to the specification of the essence of humankind; secondly, the idea that, more specifically, this phrase characterizes our form; and finally, the idea that "rational" designates a characteristic that differentiates the genus "animal." These ideas are often treated as elements of an alien and antiquated metaphysical outlook, one that modern philosophy has proved to be unjustifiable and that modern science has shown to be superfluous. I will suggest, however, that they can be understood in a way that makes them

\footnotetext{
${ }^{3}$ I discuss the attribution of this definition to Aristotle more carefully below.
} 
neither antiquated nor alien: as characterizing the distinctive categorial framework in which we must understand claims about the central powers and activities of a certain sort of living thing - a framework we constantly presuppose when we think about persons and their activities, and one whose soundness few philosophers seriously question.

A crucial implication of the Classical View, I will argue, is that rationality is not a particular power rational animals are equipped with, but their distinctive manner of having powers. Appreciating this idea will, I think, allow us to avoid certain unhappy dilemmas at which contemporary discussions in the philosophy of mind tend to arrive. In particular, I will argue that it enables us to avoid the following choice, which many authors take to be mandatory: either offer an account of cognition and action that applies uniformly to both rational and nonrational animals, or else deny that nonrational animals can literally be said to cognize and act. Furthermore, I will suggest that appreciating this idea puts us in a position to answer the common charge that conceiving of our minds as essentially rational involves a hyper-intellectualized or hyper-idealized view of how our minds operate. I will draw out these consequences in $§ 3$. First, though, I need to describe the Classical View.

\subsection{On the Classical View, although the concept rational undoubtedly has other} applications, it appears primarily as part of a definition of a certain kind of living creature. Such claims as that a certain individual has judged or acted rationally or irrationally, or that certain sorts of activities (e.g., choosing, inferring, or deliberating) are exercises of rational capacities, involve a concept whose significance must be explained by relating it to the more basic idea of a rational animal. ${ }^{4}$

The kind whose definition is of primary concern to us is of course our own kind: human beings, or in an older idiom, "man." To say that "rational animal" belongs to the definition of man is to say that it belongs to the specification of what it is to be a human

\footnotetext{
4 The occurrence of "rational" in "rational animal" thus gives what Aristotle scholars commonly call the "focal meaning" of this term: the primary meaning in relation to which various other senses of the term are to be understood.
} 
being. Aristotle is in the habit of nominalizing this phrase, so that he frequently speaks of "the what-it-is-to-be" (to ti èn einai) of a thing, and this is what comes, by way of Latin translation, to be known as its "essence." A definition explicates what it is to be a certain kind of thing, and Aristotle famously suggests that this explication should take the form of a specification of a genus under which that thing falls, qualified by some "difference" or "differences" that distinguishes its particular species within the genus. ${ }^{5}$

It is sometimes suggested that "rational animal" just is Aristotle's definition of man', but I can find no place where he says this, and a number of places where by implication he seems to deny it. It is true that he often suggests that reason (or speech, thought, or some other capacity he regards as characteristic of rational creatures) is unique to human beings; but that is not necessarily to claim that "rational animal" gives a sufficient account of what it is to be a human being, which is what an Aristotelian definition is supposed to do. A kind's essence, its what-it-is-to-be, is not merely supposed to be some property that uniquely characterizes it: thus "featherless biped" may be a predicate that characterizes human beings uniquely, but it does not ipso facto describe our essence. And there are various indications that, although Aristotle does think that human beings are essentially rational animals, he does not think "rational animal" exhausts our essence. One is that, when he discusses the task of defining "man," he frequently mentions properties (e.g., "two-footed") that would seem to belong to a specification of what particular sort of rational animal a man is. ${ }^{7}$ Another is that, in the De Anima, rational is introduced as a kind of soul on a par with vegetative and animal; but obviously the latter two are not differentiae of some particular species of life, but of whole categories of living things, of which there can be many particular species. Similarly, the concept rational animal seems to be such that other species at least could fall under it. But if that is right, then what it is to be a man must be distinguishable from what it would be to be one of these other possible species, and since by hypothesis

\footnotetext{
${ }^{5}$ On definition by genus and difference, see Topics I. 5 and VI. 4, and Parts of Animals, I. 2-3. Compare also Metaphysics VII. 12. All quotations from Aristotle in the text are from the translations in Aristotle 1984.

${ }^{6}$ See for instance Cohen 2009, §9.

7 See e.g. Categories 5, 3a21 and Metaphysics VII. 12, 1037b9-12.
} 
they would also be rational animals, "rational animal" cannot be a complete characterization of what it is to be a man. ${ }^{8}$

2.3 To understand the sense in which being a rational animal nevertheless partially characterizes the essence of man, we first need to consider what it is to characterize the essence of something. As a first approximation, we might say that to characterize the essence of an individual thing is to specify what its "being" comes to - i.e., to specify the concepts that would have to be involved in an adequate explanation of the nature of its existence. Aristotle's thought is that not everything which can be said truly about a particular individual belongs to such a specification. Only a certain sort of predicate, one that qualifies what he calls the "substance" of a thing, belongs to the specification of its essence.

A thing's substance is what it must be if it is to be at all. It is designated by some fundamental sortal predicate which the thing must bear at all times when it exists. For you and for me, the relevant predicate is: "human being." I may at a certain point in my life become a father, or be for a period an officer in the Navy, but I never became a human being (for I did not exist before I was one), and I could not cease to be one without ceasing to be, period. Furthermore, although, having been born and raised in the United States, I always was and always will be an American, still American is not a concept that must be invoked in explaining what it is for me to exist as an individual subject of predications. Thus I could informatively explain what an American is by saying: it is a human being who was born and raised within the territory of the United States. But I could not in a similar way explain what it is to be a human being by saying that it is an individual instantiating some more fundamental sortal concept, which qua individual is subject to certain further determinations. For what would the sortal concept be? It would have to be a kind such that

\footnotetext{
8 This certainly seems to have been how Aristotle was read by many medieval commentators. Thus Aquinas says that "to man as man belong rational, animal, and whatever else his definition includes" (Aquinas 1949, Part III, Para. 3; emphasis added), and Porphyry writes that "[r]ational animal is a species of animal and a genus of man. Man is a species of rational animal" (Porphyry 2003, §2, 4.30-31).
} 
there could be one of those which as a matter of fact possessed certain further properties. But sortal predicates more abstract than "human being" do not seem to characterize kinds of which there could be one just as such. "Mammal," for instance, is not a predicate that can be instanced by something that is as a matter of fact "configured human-being-ly" but might conceivably have been configured in another way so that it - that very same individual would have instead have counted as a horse. The concept mammal does not by itself suffice to sustain the idea of an individual which might be configured this way or that: there can of course be three mammals in the room, but only because there are three individuals belonging to concrete mammalian species. The possibility of there being three human beings in the room does not rest in a similar way on the possibility of there being three humans of determinate nationalities. ${ }^{9}$

These claims might of course be disputed, but they are not obviously indefensible, and I take them to be core commitments of the Classical View. On the Classical View, the concept human being is the basic concept of the kind of thing I am: for it is by being this kind of thing that I exist at all, and so the applicability of any other description to me rests on the applicability of this description. Being a human being is therefore an irreducible property of the individuals that bear it: we cannot say what it is to be a human being by specifying other more basic features individuals might have that would make them human beings.

Nevertheless, Aristotle holds that there is another sense in which we can (at least in principle) explicate what it is to be a human being: we can give a definition of human being. To say what it is to be a human being in this sense is not to specify a more fundamental kind that individuals might fall under plus some features which would make such individuals count as human beings: that, as we have seen, is something the Classical View holds to be impossible. To say what it is to be a human being is to describe, not properties of individuals that make them count as human beings, but rather to characterize the nature of the kind human being itself, the kind of thing in virtue of being which you and I are particular

\footnotetext{
${ }^{9}$ See especially Categories 5 and Metaphysics VII. 4. For a recent defense of such a standpoint on individuation, see Wiggins 2001.
} 
individuals at all. The predicates that appear in a definition of man thus attach, not primarily to individuals of that kind, but to the kind itself, and their applicability to individuals is always in an important way mediated by this more primary application. ${ }^{10}$

This is a difficult idea, but I think we can come to understand it better by reflecting on a point that Michael Thompson makes in his important paper "The Representation of Life" (1994). Thompson points out that we are all familiar with a certain mode of description of living things which is not a description of them as individuals. It is a mode of description that is familiar, for instance, from nature documentaries: "The grizzly bear digs a den under rocks or in the hollow of a tree, or in a cave or crevice. It goes into its den between October and December and stays there until the early spring. It has a protective layer of fat that allows it to stay in its den while the weather is cold. It does not really hibernate and can easily be woken up in the winter..." These sentences describe, not what this or that grizzly bear does (indeed, this one may fail to make a den, and that one may fail to go into it at the standard time) but what is done by "the grizzly bear," or by grizzly bears in general - where "in general" is heard in a special register. These sentences do not necessarily describe what holds of most grizzly bears: it may be, for instance, that, given human encroachment on their habitat, most actual grizzlies are not in a position to build up the layer of fat that allows them to survive the winter. Even so, it would be a true description of how "the grizzly bear" lives to say it goes into hibernation with a protective layer of fat. This truth seems to belong to a story about how things are supposed to go for grizzlies: a system of judgments constituting a teleologically-structured story about how they get by in the world. Recognizing this, we might try saying that the sentences describe how things "normally" or "properly" go for grizzly bears. But, as Thompson persuasively argues, this is true only if "properly" means something like "if things go right with respect to

${ }^{10}$ For these doctrines, see especially the discussion of things said of a substance "in respect of itself" (or "per se") in Metaphysics VII. 4:

The essence of each thing is that which is said of it in respect of itself. For being you is not being musical, since you are not by your very nature musical. What, then, you are by your very nature is your essence. (1029b13-1029b15)

Compare also Categories 3-5 and Metaphysics X. 9. 
being a grizzly bear" - and then determining when this condition is met simply returns us to the sentences whose truth-conditions we were trying to understand.

Thompson concludes - after showing the futility of various other proposals about how to cash out the truth-conditions of such sentences in terms of truths about individuals of the kind in question - that these truths are exactly what they appear to be, namely truths about "the grizzly bear" (or other concrete kind of living thing). They are truths whose natural expression takes the form of sentences linguists call "generics," sentences of the form: "Ss are/have/do F" or "The S is/has/does F." In general, it is notoriously difficult to give an account of the truth-conditions of such generic propositions in terms of the truthconditions of sentences about propositions of kind S. I think Thompson argues convincingly that, at least in the case of generics that characterize the natures of living things, there could not be such an account, but I will not try to present his argument here. Instead I will simply observe that, even if some account were discovered that proved to be extensionally correct, it would be implausible to suggest that our understanding of the truth-conditions of such sentences depends on our understanding specific principles connecting them with truths about individuals of the relevant kinds. Our grasp of the relevant claims seems to be a grasp of predicates applying directly to the kind, not mediately to the kind in virtue of their application to individuals of that kind. And that, in effect, is the Aristotelian thought about the predicates that appear in a definition of a certain substantial kind: they state, not features that individuals must have if they are to belong to that kind, but rather attributes that directly characterize the nature of the substantial kind itself. ${ }^{11}$

Thompson's paper also brings out the force in the idea that the application of such predicates to individuals of a given kind is mediated by their application to the kind itself. For, he argues, when I take a structure in a particular organism to be a wing, or a tooth, or when I take a certain chemical process to be a part of its digestion, or indeed when I make any judgment which implies that the subject is alive, I implicitly commit myself to various

\footnotetext{
11 The connection between generic propositions and the Aristotelian notion of essence is also noted in Moravcsik 1994, another paper to which I am indebted.
} 
assumptions about the function of such features or occurrences in the life of that kind of creature. To identify this excrescence as a wing rather than some sort of deformity is already to see it as a case of this organism's being as it is in the nature of this kind of thing to be: it is to see this aspect of its shape as a realization of a way of being shaped that has a function in the life of this kind of creature, a way of being that came to exist here - to the extent that it did - because this is the way they are. The description of the features and activities of individual living organisms thus goes with a way of seeing those individuals in which what they are like is characterized in terms of its (more or less perfect) realization of potentialities, and in which happenings in which they are involved are characterized as (more or less successful) acts of powers, where such potentialities and powers are attributable to individuals only in virtue of their being instances of a certain kind of living thing. And this mode of description is no mere superficial addition to our understanding of living things. As Thompson observes in another paper:

Even such apparently purely physical judgments as that the organism starts here and ends here, or weighs this much, must involve a covert reference to something that goes beyond the individual, namely its life form. It is only in the light of a conception of this form, however dim that conception might be, that you could intelligibly suppose, for example, that the[se] tentacles are not parasites or cancerous excrescences or undetached bits of waste. (Thompson 2004, p. 52)

But to say that judgments about individuals refer in this way to "life forms" is to say that they refer to the teleologically-organized system of generic judgments that characterize the life cycle of that kind of thing (the grizzly bear, the horseshoe crab, etc.). ${ }^{12}$ Thus, if Thompson is right, predications that ascribe vital characteristics to particular organisms are mediated by predications holding of the substantial kind per se, just as the Classical View would suggest.

2.4 It is worth emphasizing how different this way of understanding the idea of an

\footnotetext{
12 This obviously need not imply that a given judger's conception of that system is complete or even correct. But in judging that a certain vital predicate applies to a certain organism, I commit myself to assumptions about the shape that system takes.
} 
essential property is from standard contemporary approaches to the topic. ${ }^{13}$

The dominant contemporary understanding of the notion of an essential property explicates this notion in modal terms. On this view, $x$ is essentially $F$ just in case it is a necessary truth that if $x$ exists, it is $F$, i.e.:

$(N) \quad \square(\exists y(y=x) \rightarrow F x)$

The Aristotelian conception of essence presented above gives a more complex account of the relation between an individual and the properties that characterize its essence. The account involves a distinction between two questions:

(1) What is the substantial kind to which an individual belongs?

(2) What is the nature of that kind?

Question (1) is answered by a term $S$ that designates the substantial kind to which the individual belongs, as "human being" designates our substantial kind; and it is indeed the case that, on the Aristotelian view, individual Ss can only exist at all in virtue of being $S$ s. ${ }^{14}$ Question (2), however, is answered by a definition that explicates what it is to be an $S$, and the traits mentioned in this definition, although they characterize what it is to be an $S$, will not necessarily be possessed by every individual that is an $S$. The account will thus yield propositions of two importantly different types:

(E1) The essence of $x$ is to be an S.

(E2) Ss are essentially F.

Only propositions of form (E1) directly concern individuals; propositions of form (E2) are self-standing generic propositions that characterize a substantial kind as such - though of course they are connected with propositions characterizing individuals of that kind in the

\footnotetext{
${ }^{13}$ I am grateful to Dorit Bar-On for pressing me to address this issue.

${ }^{14}$ It is not clear, however, that this point is well expressed by saying, as (N) does, that such individuals are human beings in any possible world in which they exist. It is open to question whether a possible worlds framework adequately captures the relation between existing and being-a-such-and-such that holds here. Indeed, if being human beings is our way of being actual existents at all, then it is open to question whether our being human beings is well represented as a case of our having a certain property at all. I cannot pursue these questions here, however. Even if being a human being can be treated as an essential property in the manner of $(\mathrm{N})$, there are further features of the Aristotelian standpoint that decisively differentiate it from this approach.
} 
complex ways we have been considering.

It is not immediately clear how to render propositions of form (E2) in modal terms. A simple proposal would be:

$(\mathrm{N} 2) \quad \square(\mathrm{x})(\mathrm{Sx} \rightarrow \mathrm{Fx})$

That is, in all possible worlds, if something is an S, then it is F. (Other readings of the claim can be constructed by placing the necessity operator in other positions.) But the immediate difficulty for (N2) is that it plainly fails to capture what Aristotelians mean by saying, e.g., that human beings are essentially two-footed. For this is consistent, as we have noted, with the existence of individual human beings who do not have two feet. Having two feet might belong to the characterization of what it is to be a human being, yet I, who am a human being, might lose a foot without ceasing to exist (and without ceasing to be a human being). So the claim that human beings essentially have two feet does not imply a modal proposition of form (N2). And it is hard to see how any variant of this proposal can escape the objection, so long as it retains the ambition of reducing claims of form (E2) to claims about what is necessarily true of individuals. ${ }^{15}$

This fact is a reflection of the distinction between descriptions which apply primarily to a substantial kind per se and descriptions which apply primarily to particular individuals

\footnotetext{
${ }^{15}$ Similar points apply to the interesting nonstandard treatment of essence proposed by Kit Fine (see Fine 1994, 1995a, 1995b). Fine does not attempt to reduce claims about essence to modal propositions: he treats "Essentially" as a primitive operator on propositions, and seeks to explain modality in terms of essence. Nevertheless, for Fine, "[a] property of an object is essential if it must have the property to be what it is" (1995a, p. 53), and this leads him to adopt an axiom to the effect that a proposition which truly characterizes the essence of a certain kind of thing must also be true simpliciter (his axiom $\square_{\mathrm{F}} \mathrm{A} \rightarrow \mathrm{A}$ : see Fine 1995b, p. 247 - but note that the interpretation of this axiom is complicated by the fact that Fine's " $\square$ " is not a function applying to predicates but an operator on propositions, which Fine introduces by stipulating that the proposition " $\square_{F} A$ " means roughly "The proposition $A$ is true in virtue of the nature of objects which are F"). Hence, in Fine's system, the claim that it belongs to me essentially as a human being that I have two hands will presumably be schematized as
}

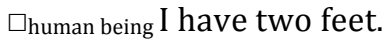

And this will imply

I have two feet.

But on the understanding of essence proposed here, it might be true that human beings essentially have two feet, and thus true to say of me that, as a human being, it belongs to my essence to have two feet; and yet this does not rule my actually failing to have two feet, whether through defect of birth or misadventure. 
of that kind, a distinction which is crucial to the Classical View but which contemporary treatments of essence generally do not draw. On the Classical View, propositions about the essential features of human beings are propositions about the kind human being itself, and there is no immediate inference to be drawn from such truths to freestanding propositions about what particular individuals of this kind are like. This is not, of course, to suggest that truths about the kind and truths about individuals of that kind are simply unconnected: they are connected inasmuch as the truths about the kind describe how things go for individuals of that kind if nothing interferes. But to allow for the possibility of interference is to allow for the possibility of exceptions which do not disprove the rule.

2.5 Having said this much about living things and their essences in general, we can return to rational animals in particular. We noted earlier that "rational animal" seems on the Classical View to be only a partial characterization of the human essence. It has the form of a specification by genus and differentia, but the kind of thing it specifies seems to be still generic with respect to human beings. What then does it characterize? Does it, like "mammalian," merely pick out a set of traits that certain animal species exhibit? Aristotle seems to regard the rational/nonrational contrast as marking a deeper sort of distinction than that. One indication of this is the fact, mentioned earlier, that he treats rational as on a par with vegetative and animal - as designating one of the three fundamental kinds of soul. But what is a kind of soul?

To answer this question, we must recall some points about how Aristotle explains the notion of soul in general. Aristotle famously thinks of living things in hylomorphic terms, as cases of matter of a certain sort bearing a certain form. A soul, for Aristotle, is that the form of a living thing: it is that structuring principle in virtue of which matter of a certain sort constitutes a living thing. ${ }^{16}$ To be "ensouled" is to partake of the mode of organization characteristic of life. What sort of organization is that? Aristotle holds that this question

\footnotetext{
${ }^{16}$ Compare De Anima II. 1 (412a16-21).
} 
cannot be answered in a completely general way. There are three different ways of being a living thing, ways which are not just unrelated, but which are not definable by reference to a single abstract schema. Rather, these three modes of life are in a certain way successive not in their order of appearance in the world, but in the way they are defined. To understand what an animal soul is requires understanding how animality transforms the mode of organization characteristic of a nutritive soul, the type of soul that appears primitively in plants; and to understand what a rational soul is requires understanding how rationality transforms the mode of organization characteristic of an animal soul. ${ }^{17}$

This implies, on the one hand, that the idea of being rational has content only in virtue of building upon the idea of being an animal, a living thing capable of negotiating the imperatives of its life by exercising the powers of perception and desire-governed action. But it also implies, on the other hand, that what it is to be an animal is fundamentally transformed where rationality is present. "Rational" counts as a differentiating predicate of "animal", rather than merely as the name of a trait that certain animals exhibit, in virtue of the fact that what is rational differs in its way of being an animal from what is not. Thus Aristotle explains the notions of genus and differentia as follows:

By genus I mean that one identical thing which is predicated of both and is differentiated in no merely accidental way... For not only must the common nature attach to the different things, e.g. not only must both be animals, but this very animality must also be different for each... For I give the name of 'difference in the genus' to an otherness which makes the genus itself other. (Metaphysics X. 8, 1057b38-1058a7)

If being rational did not transform what it is to be an animal, a discussion of rationality would not need to appear in a general account of what it is to live: "rationality" would just be a characteristic of certain animal species, which are living things in whatever sense any animal species is a living thing. This, presumably, would be Aristotle's attitude toward "mammality". But it is not his view of "rationality": he holds that being rational transforms the nature of being an animal, and thus constitutes a new way of being a living thing. And

${ }^{17}$ See De Anima II. 2-3, which argues that "life is spoken of in many ways" (413a22) and therefore that "we must inquire in each case what is the soul of each thing, what is that of a plant, and what is that of a man, or a beast" (414b31). 
since "for living things, to be is to live,"18 this implies that a rational animal has a distinctive form of essence, a distinctive type of "what-it-is-to-be."

This is the thought at which I have been aiming to arrive. Let me clarify how I understand it. We were asking what kind of distinction the rational-nonrational distinction is supposed to be, and in what sense it is supposed to be a deep distinction, one that makes for a difference between kinds of minds. We have arrived at the following conclusions. First, on the Classical View, "rational" does not differentiate us merely because it names a trait that happens to be unique to humans. It belongs, rather, to a characterization of our essence, which is to say, to an account of what our existing as particular individuals comes to. As such, it is predicable of us as individuals only in virtue of being predicable of the substantial kind to which we belong (namely: human being). Furthermore, it characterizes this kind not in the way that concrete descriptive predicates like "mammalian" or "twofooted" do: it does not specify the specific content of our essence, but the form of essence that we have. We could put it this way: "rational" specifies the sort of frame that undergirds any concrete description of what it is to be a human being. For it does not specify a particular characteristic that we exhibit but our distinctive manner of having characteristics. This, I believe, is the significance of saying that "rational" characterizes the form of human being. A substantial kind is, as we have seen, the subject of which essential traits are predicated; and where we have a different form of kind, the predicates that characterize that kind per se, and in consequence the predicates that apply to individuals only insofar as those individuals belong to that the kind, will admit of a different sort of significance than they would have in application to kinds with other forms. The predicate that differentiates one form of life from another thus does not name a concrete characteristic (or set of characteristics) that certain species of living things possess; it marks the possibility of a different form of predication of vital characteristics in general.

\footnotetext{
${ }^{18}$ De Anima II. 4, 415b13.
} 
2.6 I have stated this point very abstractly. Some examples will help to make its significance clearer.

Let us start with a simpler case, namely the difference between a plant and an animal - for this too is a difference of form, on the Classical View. Consider what it means to talk about activity in the case of a plant and in the case of an animal. Many people will be tempted to say that plants do not act at all, and there is of course a sense in which that is right: they do not act in the sense in which animals act. Nevertheless, there are clearly some episodes in the lives of plants in which they figure as agents rather than as mere patients. When a tree is chopped down, it is a patient; but when it grows a new branch, or flowers in the spring, it is an agent: the latter are things the tree in some sense does, not things that are done to it. Now, the opposition between agency and patiency depends in general on where the primary explanation of the relevant event or process lies. Thus growing a new branch counts as something the tree is doing because, although various environing circumstances may facilitate this happening, the primary explanation of it is to be sought simply in the nature of the tree itself (as characterized in a system of generic propositions of the sort discussed earlier). The tree's growing a new branch is thus in a broad logico-grammatical sense its own act, one expressible in an active-voice progressive judgment that has the tree as its subject. And the act is even goal-directed in a clear enough sense: trees grow branches precisely because having branches permits them to have an extensive canopy of leaves that absorb sunlight. Nevertheless, when we speak of the goal-directed acts of an animal, we are clearly speaking of agency and goal-directedness in an altogether different register. It is not merely that an animal can do more than a plant; it is that talk of "doing" can apply in a wholly new way to an animal. ${ }^{19}$

I think this is intuitively clear, but one way to see the underlying basis of our intuition here is to reflect on the fact that descriptions of the here and now can never enter into the characterization of the "acts" of plants except in the form of triggerings, helps or

\footnotetext{
19 Thus Aristotle says that plants have "movement in respect of growth and decay" but not "movement in respect of place," which is a different form of movement: see especially De Anima II. 4 and III. 9.
} 
hindrances. The root of a tree can be growing round a stone, but it would be at best sentimental to suggest that the root is growing in a certain way in order to get round this stone. The presence of this stone here and now does not inform the content of the tree's act of root-growing, that toward which it is goal-directedly tending. The tree's roots simply grow, as far as possible, according to a certain pattern: the stone enters as a hindrance to this growth, something that interferes, and hence qualifies the sense in which the shape of the resultant growth can be understood as the tree's own doing, rather than as a reflection of something done to it. An animal, by contrast, can act with respect to the here and now: descriptions of present circumstances can enter into the content of what it is doing. Its capacities for perception and desire transform its mode of being alive precisely because they make this possible: they open animal life, not merely to the causal influence of present circumstances in the form of triggering, hindrance, or facilitation, but to the kind of influence that enters into the constitution of what the subject is doing. Thus an animal can try to get that object, or do something in order to avoid this obstacle.

The thing that can fill the " $\mathrm{A}$ "-slot in "S is doing $A$ " will thus be an " $\mathrm{A}$ " of a fundamentally different kind where the subject in question is an animal. It will be, not merely a type of content that adverts to some generic form of activity (growing a branch, flowering, etc.), but a type that embraces particularity within itself: the general sort of thing the animal is doing (hunting something, fleeing something, playing with something, etc.) has - to borrow a Fregean phrase - an unsaturated position, one that waits for perception (or, in more sophisticated animals, memory, imagination, etc.) to fill it. The sorts of things that plants can do contain no such gaps. And it is just another aspect of the same point to say that animals act as individuals in a way that plants do not. A particular oak can be growing a new branch, but the explanation of its doing so does not really look to it in particular: it is just doing the kind of thing that all healthy mature oaks do at this time of year, given enough sunlight, enough water, etc. It has not determined that this should occur, although various things about it and its circumstances certainly affect whether the general disposition of its kind will be realized here and now. Nevertheless, the fundamental explanation of its act is 
just a certain generic fact about its kind: this is what they do. The here and now enters only as trigger, help, or hindrance. To understand why an animal is doing what it is doing, by contrast, we have to look to this particular one, for what it pursues is not simply fixed by the laws of its kind, but involves facts about the experience of this one in particular. ${ }^{20}$

I have been describing the differences between plant and animal activity in some detail in order to bring out what it might mean to say that, in contrast to a predicate like "mammalian" or "land-dwelling," the predicate "animal" does not name a concrete characteristic exhibited by certain kinds of living things, but rather marks the possibility of a distinctive form of predication of characteristics to such things. My aim has been to suggest that, although both plants and animals can be said to do things, can be characterized as agents of some of what happens to them, can perfectly correctly and literally be said to pursue goals, etc., nevertheless the manner in which such predications apply is different in the two cases. It is not merely that animals can do things that plants cannot; it is that the whole language of "doing" takes on a new significance, a new logical character, when we turn from plants to animals. I think similar points could be made about predications in each of the various Aristotelian categories: an animal admits, in a manner fundamentally different from a plant, of, e.g., having something, being acted on, being qualified in a certain way, and even of being in a certain place and of being one thing. ${ }^{21}$

\footnotetext{
20 If the depth of this difference does not seem evident, it may help to reflect on the distinctive kind of failure that animal agency makes possible. If a cat is chasing a certain mouse and does not catch it, but manages as it happens to pounce on a different mouse, then although the cat has in one sense got was it was after (namely, a mouse), there is clearly a sense in which it has failed to get what it was after (namely, this mouse, the one it was chasing). By contrast, if a tree's roots are taking up water, and we somehow contrive to replace the water molecules that would ceteris paribus have been taken up with other water molecules, then although the circumstances of the tree have changed, there is surely no purpose belonging to the tree which it has failed to achieve. Plants, as plants, simply do not engage with the particular things present here and now in this sort of way. (This is true even of the Venus Flytrap, which reacts to stimuli in a way that bears an uncanny resemblance to animal percipience. The Flytrap is triggered to activity by some particular fly's touching its trigger-hairs, but then it simply does what all such plants do when those hairs are touched: it snaps shut. The snapping is triggered by a particular fly, but the act itself instances a completely generic mode of activity which is not aimed at, but merely occasioned by, this fly in particular.)

${ }^{21}$ This across-the-board transformation is a reflection of the primacy of the category of substance (see esp. Metaphysics VII. 1): where the type of substance is transformed, the significance of predications in other categories undergoes a correlative transformation. Thus where two types of substance are generically alike but specifically different (e.g., both living but only one animal), this introduces the possibility of predications in the other categories that are also generically similar but specifically different
} 
This is not to suggest that every predicate in each of these categories applies differently to animals than to plants: I take it that there is no fundamental difference between, say, talking about the weight of a plant and the weight of an animal, or between talking about the color of a plant's leaves and the color of an animal's fur. My claim is not that animals do not admit of predications of the same character as those that apply to plants, but that they $d o$ in addition admit of predications of a distinctively different character, and that this is the kind of difference that the term "animal" marks. In a fuller discussion, I would also want to argue that these distinctive predications characterize the core of what it is to be an animal; for it is only in virtue of what an animal has, does, and is in this distinctive register of having, doing, and being that it exists as a particular individual at all, and hence its bearing these predicates is the principle of $i t s$ bearing whatever other predicates it bears (weight, color, etc.). But to develop this idea would take us too far afield; the crucial point for present purposes is that the animal/nonanimal contrast differentiates two forms of life: it differentiates living kinds, not merely in respect of certain particular characteristics they possess, but in their whole manner of having characteristics, the form that predications of being, having and doing can take for them.

Likewise, on the Classical View, the rational/nonrational contrast marks this sort of difference. A rational animal is capable, not just of being, having, and doing more than a nonrational creature, but of being the subject of ascriptions of being, having, and doing in a distinctive sense. Consider action once again as an illustration. It is perhaps even more obvious in this case that the generic notions of being an agent, doing something, and pursuing a goal apply to both rational and nonrational animals. What is perhaps less obvious is that agency, doing and goal-directedness take a different form in the rational case. Nevertheless, it is widely recognized that there is a sense of "doing something" that applies only to rational creatures: we are the only creatures that act intentionally. Furthermore, it is widely conceded that a condition of the applicability of ascriptions of doing in this

(e.g., both of vital activity but only one of animal action). 
distinctive sense is that the creature should be doing what it is doing knowingly, in virtue of exercising its power to determine what ends are worth pursuing and how to pursue them. On the Classical View, the power to act in this distinctive sense - to engage in doings whose ascription implies that the subject knows what he is doing and what for - is the special prerogative of rational creatures. Thus Aquinas holds that although nonrational animals can be said to intend an end and act voluntarily in pursuit of it in "an imperfect sense," they are not capable of intention or voluntary action in "the perfect sense," since they do not ordain their movement to an end in virtue of knowledge of that end "under the aspect of an end". Rather, they merely apprehend an object they desire and act from instinct or acquired habit in pursuit of it. ${ }^{22}$

Some will want to argue that various species of nonhuman animals are capable of more than this. I take no position on this issue. My aim here is not to argue for a certain classification of this or that species of living thing, but to point out a kind of distinction that seems at least intelligible, whatever one thinks of its application in particular cases. If the distinction is intelligible, then talk of animal "doing" (and relatedly, of animal agency, responsibility, pursuit of an end, etc.) admits of two different registers, one nonrational and the other rational. ${ }^{23}$ I think it would be possible to show that this distinction corresponds to a difference in the form of the " $\mathrm{A}$ " that can be the content of rational doing, and in the manner in which the predicate "is doing A" attaches to an individual rational subject. But to develop these differences would involve beginning to give a substantive theory of rationality, and that is not my purpose here. My aim is just to point out the possibility of a certain sort of conception of the difference that rationality makes, one that would give sense to the idea of a different kind of mind.

\footnotetext{
${ }^{22}$ See Summa Theologica, IaIIae, Q. 6, A. 2 and Q. 12, A. 5.

23 This is how I understand G. E. M. Anscombe's cryptic claim that the term "intentional" does not name "an extra feature" that accompanies certain actions but rather "has reference to a form of description of events" (see Anscombe 1957, $\S \S 19,47$ ). Her aim is to argue that "intentional action" does not simply pick out a certain class of events but a certain distinctive type of event-predication, one that can only apply to creatures who can be the subject of the special sort of "why?"-explanation that she identifies, one whose application presupposes that the subject in question itself knows what it is doing and why, and acts precisely in virtue of that knowledge.
} 
The quotation from Herder at the head of this paper captures the crux of this conception: the idea is that our rationality does not merely increase the extent of our ability to do things in the sense that nonrational animals can already be said to do things. Nor again is "reason" the name of a particular power - like sight or hearing or the power to walk on two legs - which enables us to do some specific sort of thing, but to do it in the same general sense of doing that applies to the powers from which it is differentiated. Rather, as Herder puts it, "reason" names "the whole organization of all human powers," an organization which determines "a quite different sort of orientation and unfolding of all powers." What he means, I think, is that our rationality transforms the sense in which powers and their corresponding acts are ascribable to us. It marks a new form of powerand act-predication, in the sense I have been trying to explain. And as a characterization of our essence, it implies that reference to powers of this distinctive form belongs to an account of the sense in which we exist, as individual subjects of predication, at all. ${ }^{24}$

\section{Applications}

3.1 This reconstruction of the Classical View will have been worthwhile if it helps us with difficulties that face us here and now. I believe it does. Let me conclude by mentioning some common objections to the idea of a difference in kind between rational and nonrational minds which the foregoing reflections help us to answer.

The idea that reason brings with it a new kind of mind, one that admits a distinctive form of predication, is not without recent defenders. Something like this view has been defended, for instance, by Donald Davidson, who famously claimed, first, that to understand our kind of mind, we must focus on a certain class of predicates, namely those that ascribe so-called "propositional attitudes"; and second, that the application of such predicates is governed by a "constitutive ideal of rationality" (Davidson 1980, p. 223). To claim that

\footnotetext{
${ }^{24}$ A distinction whose most immediate effect is, as Herder suggests, on our sensing, cognizing, and willing nature. These are the types of predication most immediately affected because they are the types specific to animality, which is the genus of substantial being that is differentiated by rationality.
} 
rationality makes a constitutive difference to the kinds of predicates we are capable of bearing amounts, I take it, to claiming that we are not merely capable of representing and doing more than nonrational animals, but that we can figure as the subject of predications of representation and action of a distinctive form, a form that applies to us only in virtue of our rationality. Now, Davidson's claim has been influential, but it has also faced various recurrent objections. We might think of these as falling under two heads: (i) objections to the idea that rationality can make a constitutive difference to the kind of representing and acting of which we're capable, and (ii) objections to the idea that reference to a mere ideal of rationality can play a crucial role in determining what is actually true about us. I want to say something about each of these sorts of objections, and how the foregoing discussion bears on it.

3.2 One common objection to views like Davidson's begins from the observation that, except when we are defending a philosophical view that requires us to say the contrary, we all take it for granted that many sorts of nonhuman animals can believe things about their environment, can learn from past experience, and can act intelligently in pursuit of things they desire. All of these descriptions seem to apply perfectly literally to nonhuman animals, and they seem to figure in genuine explanations of how they behave. And this impression is only reinforced by rigorous studies of animal behavior. It would thus be perverse - so the objection goes - to deny that nonhuman animals can believe, desire, and so on; but this is exactly the sort of perversity involved in the claim that only rational animals can have propositional attitudes. If the literal application of propositional attitude ascriptions presupposes rationality, then rationality must be present quite generally in the animal kingdom; while if rationality is something special to human beings, it cannot be presupposed in the application of propositional attitude talk. At any rate, the objectors conclude, if there is a difference between our representing the world and that of "lower" animals, it must be merely a difference in the sophistication of the representational contents we can entertain and the complexity of the operations we can perform on them, not a 
distinction between altogether different kinds of representational states.

I think this objection rests on an assumption that the foregoing discussion has given us the resources to question. The assumption is that a psychological or epistemic concept which applies both to rational and to nonrational animals must be susceptible of a single, undifferentiating account that covers both sorts of application. We might call this the Univocality Assumption, for it amounts to the claim that such concepts must be treated as univocal in their application to rational and nonrational animals. This assumption manifests itself in the frequently heard insistence that an account of belief, warrant, knowledge, etc. must not make any demands that a nonrational animal could not meet, since nonrational animals plainly hold beliefs, possess warrant for their beliefs, have knowledge, and so on. It should be clear that this inference is only valid given the Univocality Assumption, for only if an account of these concepts must not differentiate between rational and nonrational animals does the fact that we speak of nonrational animals as holding beliefs, being warranted, etc., show that our account of the application of such concepts to humans cannot make demands that a nonrational animal could not meet.

Must we make the Univocality Assumption? In his recent "Perceptual Entitlement,"

Tyler Burge writes:

Children and higher nonhuman animals do not have reasons for their perceptual beliefs. They lack concepts like reliable, normal condition, perceptual state, individuation, defeating condition, that are necessary for having such reasons. Yet they have perceptual beliefs. There is no sound basis for denying that epistemology can evaluate these beliefs with respect to norms governing their formation, given the perspectival limitations and environmental conditions of the believer. There is no sound basis for denying that epistemology can evaluate their perceptual beliefs for epistemic warrant. (Burge 2003, p. 528)

I think there is a reading of what Burge says here on which it is undeniable: nonhuman animals patently respond to the world on the basis of representations of what is the case, representations that we have every right to call "beliefs," representations concerning which we can certainly raise questions of warrant. But Burge makes these points in the context of attacking the thesis - which he associates with authors such as Sellars, Davidson, and 
McDowell - that the kind of warrant that a rational creature has for its beliefs must be a warrant that "lies within 'the space of reasons'." Indeed, he writes as though these points themselves constituted a refutation of the thesis: if nonhuman animals can have beliefs, and be warranted in having them, then, Burge reasons, being warranted in a belief cannot depend on capacities that nonhuman animals do not possess. ${ }^{25}$

But surely this inference reflects a blinkered view of the options. Whatever exactly it means to claim that a rational creature's warrant must "lie within the space of reasons," a sensible defender of this claim should not hold this to entail that nonhuman animals cannot have perceptual beliefs, or be warranted in having them. He should hold, instead, that the concepts of belief and warrant have a different application here from the one they have in connection with nonrational creatures - that with the advent of reason comes a new form of belief and new standards of warrant associated with it. To hold that concepts such as belief and warrant apply in one way to rational creatures and in a different way to nonrational animals need not be to suggest that we are merely being ambiguous when we speak of "belief" and "warrant" in connection with creatures of both kinds. It might be rather to claim that merely animal belief and rational belief, merely animal warrant and rational warrant, are different species of the same genus. And as we have seen, the Classical View holds that the rational-nonrational distinction allows for precisely this combination of generic similarity and specific difference in the way basic types of predicates apply. Thus, just as both rational and nonrational animals can be said to act, although the idea of action is applied in a distinctive register in the rational case, so too it might be that both rational and nonrational animals can be said to represent what is the case, although again, the idea of such representation is applied in a distinctive register in the rational case. We might choose to reserve the word "belief" for the distinctively rational case or we might not: either choice would amount to a bit of terminological legislation, and either would be acceptable so long

\footnotetext{
${ }^{25}$ Burge's views on these topics deserve a much fuller discussion than I can give them here. I quote him simply as exemplifying a widespread readiness to assume the univocality of various important cognitive concepts across the rational-nonrational boundary. For fuller presentation of Burge's position, see Burge 2010. I hope to address Burge's views in detail in future work.
} 
as we did not lose sight of the specific combination of likeness and difference that obtains here.

My present aim is not to defend these views about rational belief but merely to note their possibility. This is at least an intelligible sort of position to take, whether or not it is defensible in the case at hand. The Univocality Assumption in effect rules out such a position with regard to concepts such as belief, knowledge, inference, and warrant. But the claim that these concepts have a different and more stringent meaning in application to rational beings than they have in application to nonrational animals at least deserves a hearing. If such a position were vindicated, then, despite what Burge says, we would have a basis for denying that epistemology can evaluate the perceptual beliefs of children and nonhuman animals for warrant in the sense of warrant that is proper to rational beings.

There is a tendency, in studying the differences between human beings and nonhuman animals, to look for some crucial experiment that will either vindicate or disprove the idea that there is some basic cognitive difference between them. Thus people study whether other primates can use tools, can recognize themselves in a mirror, can learn to use a symbolic system that looks like a human language, etc. I think these studies are fascinating, but insofar as they are supposed to test the proposition that human beings are rational in a sense that other primates are not, I think they rest on a distorted conception of what this fact would have to amount to. If the Classical View is right, we should not expect the rational-nonrational contrast to manifest itself primarily in the fact that rational creatures can do some specific thing which nonrational creatures cannot. Rather, we should expect that the cognition and action of rational creatures is pervasively, essentially different from the cognition and action of nonrational creatures. That there should be analogies between human tool use and things done by other primates, between human language and the communicative activities of other primates, etc. - this is only to be expected, for it is granted on all sides that their powers fall under a common genus. The crucial question, though, is whether we are speaking in the same register when we say that we and they "use tools," or "communicate," or whatever. And the way to answer this question is not to fixate 
on some particular pattern of behavior taken in isolation - comparing human mirrorbehavior with chimpanzee mirror-behavior, or the human readiness to use a hammer to drive a nail with the chimpanzee readiness to use a stick to get ants out of a hole in the ground - but rather to consider the general shape of the life-form of the kind of creature in question, the system of generic propositions that characterizes their way of living and the forms of explanation that relate individuals to those generic truths. Do these presuppose the capacity for reflective thought or do they not? To make such a determination will involve a holistic consideration of the form of life in question, but it is not a determination made without an empirical basis, nor is it even a particularly difficult one to make. If the difference between a rational and a nonrational creature seems unclear or insignificant, this may be because we are looking for it in the wrong place. ${ }^{26}$

\subsection{A second common objection to views that posit an essential difference between} rational and nonrational cognition is that they tie propositional attitude language to a framework that is too idealized to be plausible. Davidson says that we understand the significance of propositional attitude ascriptions by reference to a constitutive ideal of rationality, and that, in determining what attitudes people hold, we must apply a "principle of charity" which requires us to find in their thought and action as much rationality as possible. But what justifies us in supposing that actual people will live up to this ideal? Aren't tendencies to inconsistency, to weakness of will, to rash judgment, and so on, as real a part of the human constitution as any tendency to get things right? If this is not already obvious to untutored observation, the objectors note, it is amply confirmed by rigorous studies of biases in human choice and judgment. As Stephen Stich puts it in his essay "Could Man Be an Irrational Animal?":

Aristotle thought man was a rational animal. From his time to ours, however, there has been a steady stream of writers who have dissented from this

\footnotetext{
${ }^{26}$ For suggestive discussion of empirical work on the distinguishing features of human cognition that is consistent with the standpoint developed here, see Tomasello 2001. Tomasello is expert at bringing out how - as I would want to put it - our capacity for discursive thought transforms the sense in which we are capable of various forms of intelligent activity.
} 
sanguine assessment... During the last decade or so, [the] impressionistic chroniclers of man's cognitive foibles have been joined by a growing group of experimental psychologists who are subjecting human reasoning to careful empirical scrutiny. Much of what they have found would appall Aristotle. Human subjects, it would appear, regularly and systematically invoke inferential and judgmental strategies ranging from the merely invalid to the genuinely bizarre. (Stich 1985, p. 115)

The existence of such biases is intelligible enough: given that we have finite time to think about the choices we make, and given that our ancestors faced certain kinds of situations where a rapid judgment or choice was called for, it might very well have been adaptive for us to possess certain "nonideal" tendencies in our judging and acting. But then presumably the way to interpret the attitudes people hold is not necessarily to assume that their system of attitudes is as rational as possible. ${ }^{27}$

Again, I think this objection rests on an assumption that our reflections have put us in a position to question. The assumption is on display in Stich's remark, which evidently presupposes that the idea that man is a rational animal must be taken as a claim about how most men think most of the time. Otherwise, how could it be a threat to this idea that human subjects regularly and even systematically make invalid inferences or judge questions on unsound bases? But as we have seen, the claim that man is a rational animal is not meant as some sort of statistical generalization. It is a claim about our essential nature, about what it is to be a human being, and to say that it is in our nature to be rational is not necessarily to say that most members of our species draw rational inferences most of the time. This is connected with a point that came up in our discussion of the grizzly bear: the powers and activities that belong to the essence of a certain kind of creature are not necessarily powers and activities that most such creatures exhibit. They are powers and activities that belong to an account about how creatures of that kind exist - an account whose exemplification in any given case is subject to all the sorts of obstacles and interferences that the world can produce, but which nevertheless supplies the explanatory principle in relation to which what does occur is intelligible. For, as Aristotle observes, the

\footnotetext{
${ }^{27}$ For a lucid statement of this sort of objection, see Cherniak 1981.
} 
account of a power figures not only in the explanation of cases in which the power is successfully actualized, but also "by negation and subtraction" in the explanation of cases in which it is not successfully actualized. That is to say: we understand the shape that things have taken in such cases precisely by understanding how the normal course of things has gone awry, either because it has been interfered with (negation) or because some precondition was missing (subtraction). ${ }^{28}$

We can call the assumption that statements about the nature of a certain kind of living thing must be read as involving an implicit quantification over (all or most) individuals of that kind the Quantificationalist Assumption. We have seen that this assumption embodies a basic misunderstanding of the logic of essentialist claims. The claim that it is an essential property of horses to have four legs (or more simply: that the horse has four legs) is not falsified by the existence of three-legged horses. It would not necessarily be falsified even if actual horses for the most part had three legs. Likewise, if the proposition that human beings are rational animals, and the more specific claims of essential connection that articulate the content of this proposition, are claims about what it is to be a human being, then the way to evaluate these claims is not to ask whether human beings for the most part give cogent accounts of their reasons for belief, draw inferences in accordance with the laws of logic and probability, or choose in accordance the principles of decision theory. The way to evaluate such claims is rather to ask what kinds of powers are exercised in human

${ }^{28}$ See Metaphysics IX. 2, 1046b13. Compare also the way Herder responds to an objection to the claim that the power of speech is part of our essence as human beings:

'But those savage human children among the bears, did they have language? And were they not human beings?' Certainly! Only, first of all, human beings in an unnatural condition! Human beings in degeneration! Put the stone on this plant; will it not grow crooked? And is it not nevertheless in its nature an upwards-growing plant? And did this power of straight growth not express itself even in the case where the plant entwined itself crookedly around the stone? (Herder 2002, p. 93)

The connection between rationality and language is not my topic here; what interests me is the kind of response Herder is offering. The response is: Pointing to cases in which $S$ s are not $F$ does not necessarily falsify the claim that it is essential to being an $S$ to be $F$, for it may be that cases of an $S^{\prime}$ s not being $F$ are intelligible precisely as cases of a power to be $F$ operating under interference. For helpful discussion of the idea of powers and their fallibility, and of the ways in which they can figure even in the explanation of their failed acts, see also Kern 2006, Chs. 6-8 and Rödl 2007, Ch. 5. 
thinking, what should count as the normal operation of such powers, and what should count as malfunctions calling for special explanation. The claim that these powers belong to human nature is entirely consistent with the observation that we very often fail in their exercise. Indeed, it is consistent with the observation that there are human beings who never attain to these powers at all. For even human beings who lack these powers belong to a species whose form of life involves the development of these powers: they are individuals whose potentiality to develop such powers has not been realized, and their minds are thus defective in an important way. A nonrational animal, by contrast, does not count as defective for want of the capacity to deliberate, to reflect on its own beliefs, to produce reasons for what it believes, etc.

The idea that ascriptions of propositional attitudes to human beings make reference to an ideal of rationality must be understood against the background I have just been sketching. To say that the application of concepts of belief and desire to a human subject presupposes a constitutive ideal of rationality is not to claim that it is a necessary condition for the application of these concepts that we find that subject for the most part rational in his beliefs and choices. The point is rather that the fundamental employment of these concepts is one in which they figure in representations of a subject as believing and acting for adequate reasons, grasped as such - as exercising powers to get things right in the distinctive way in which rational creatures can get things right. I do not claim that this is consistent with everything Davidson says about idealization, charity, etc.; but I think it captures what is insightful in his view. Of course a person can believe irrationally and act irrationally, but, if Davidson is right, what underwrites our recognition of such cases as involving irrational beliefs and irrationally-efficacious desires is our grasp of the role of these concepts in a framework of rationalizing explanation. We could put it this way: cases of believing and acting rationally are the ones we must consider in understanding the "what-itis-to-be" of belief and desire.

A common contemporary opinion - often expressed in newspapers and magazines, but also, I think, held by some philosophers - is that someone who asserts a difference in 
kind between rational and nonrational animals must be intent on exalting human beings above all other living creatures. No doubt there have been defenders of the rationalnonrational distinction who have had such aims, but the idea that this is the basic motive for philosophical interest in the concept of a rational animal seems to me mistaken. The interest of this concept does not depend on a concern with drawing comparisons. The claim that we human beings possess a distinctively rational kind of animal mind embodies a thesis about the framework in which to understand our own minds, a thesis we can accept without adopting any view about the minds of other animal species. Roughly stated, the thesis is this: an account of our minds must not treat rationality as an isolable capacity belonging to a kind of animal mind whose other capacities could be realized, essentially unchanged, in a mind lacking this special further power. The claim that rational animals have a distinctive kind of animal mind thus implies that rational capacities for perception and desire cannot be explained as: the kinds of capacities for perception and desire to be found in nonrational animals, supplemented with a further, independent power to regulate these capacities in the light of reflective reasoning. Rather, an account of our sort of perceiving and desiring must itself refer to the role of these capacities in supporting a specifically rational form of life. ${ }^{29}$ If this is right, we are not merely animals who are in fact rational; we are essentially rational animals.

\subsection{To query the Univocality Assumption and the Quantificationalist Assumption is not}

yet to demonstrate the need for a basic distinction between rational and nonrational minds, nor is it to give a substantive account of what rationality amounts to. ${ }^{30}$ But it is, I hope, to

\footnotetext{
${ }^{29}$ For further development of this idea, see my "Tack-on Theories of Rationality: A Critique."

${ }^{30} \mathrm{An}$ adequate treatment of these issues would need to begin, I believe, by contesting the idea that it is simply an empirical observation about human beings that they are rational animals. I think the claim that human beings are rational animals is grounded, not fundamentally in empirical observation, but in selfconscious reflection. One way to see this is to consider that each of us can exhibit for himself the grounds for this definition simply by reflecting on the question "What sort of creature am I?" For the power exhibited in even considering this question - the capacity to reflect on a question and form a view on the basis of grounds recognized as such - is the power of rationality itself. So the idea that we are rational beings is an idea that each of us can verify for himself simply by considering the question. And if to be an animal is to be a living creature capable of perception and desire-governed action, then the fact that we
} 
remove some important obstacles to such an account. If I have shown that these obstacles

depend on questionable assumptions about the logic of essentialist claims, and that the

Classical View of the rational-nonrational distinction offers an alternative to these

assumptions, I have achieved my purpose here. ${ }^{31}$

are animals is also not something we need discover about ourselves by observation. The fact that we are subject to perceptual appearances of the world around us, feel desires for things, and make choices about what objects to pursue, are also facts which belong immediately to our self-conscious, nonobservational knowledge of ourselves.

The characterizations of human beings as rational, and as animals, thus seem to articulate facts we are in a position to know, not primarily by looking at ourselves, but, so to speak, by looking into ourselves - facts we are in a position to know about our own minds in virtue of self-consciously having minds of the relevant sort. We could therefore say - switching philosophical idioms - that the concept rational animal is a "concept of reflection" in Kant's sense: it is a concept whose source lies in our reflective consideration of our own cognitive activity, rather than in our empirical observation of particular objects with which our cognition is concerned (compare Critique of Pure Reason, A260/B316). The fact that we have this sort of access to our rational nature is, I believe, what underwrites Kant's confidence that this nature can be investigated systematically and completely by philosophy. Thus he remarks at the beginning of the first Critique:

I have to do with nothing save reason itself and its pure thinking; and to obtain knowledge of these, there is no need to go far afield, since I come upon them in my own self. (Kant 1998, Axiv)

This is obviously only sketch of a program for grounding the concept rational animal. I hope to pursue these matters further in future work.

${ }^{31}$ For responses to earlier drafts of this paper, I am indebted to audiences at Auburn University, the University of Chicago, and the Universität Leipzig. I am especially grateful to Dorit Bar-On, Jim Conant, Matthias Haase, Sean Kelsey, Eric Marcus, Sebastian Rödl, and Pirimin Stekeler-Weithofer for comments and advice. 


\section{References}

Anscombe, G. E. M. 1957. Intention. Blackwell.

Aquinas, T. 1948. Summa Theologica. Trans. Fathers of the English Dominican Province. Benziger Bros.

. 1949. On Being and Essence. Trans. A. Maurer. Pontifical Institute of Medieval Studies.

Aristotle. 1984. Complete Works of Aristotle: The Revised Oxford Translation. Ed. J. Barnes. Princeton University Press.

Bennett, J. 1964. Rationality. Routledge.

Boyle, M. Unpublished ms. “Tack-on Theories of Rationality: A Critique.”

Burge, T. 2003. "Perceptual Entitlement." Philosophy and Phenomenological Research, 67, 3, pp. 507-548. . 2010. Origins of Objectivity. Oxford University Press.

Cherniak, C. 1981. “Minimal Rationality.” Mind, 90, 358, pp. 161-183.

Cohen, S. M. 2009. "Aristotle's Metaphysics." The Stanford Encyclopedia of Philosophy (Spring 2009 Edition), ed. E. N. Zalta. URL = <http://plato.stanford.edu/archives/spr2009/entries/aristotle-metaphysics/>

Davidson, D. 1980. “Mental Events.” In his Essays on Actions and Events. Oxford University Press.

Fine, K. 1994. "Essence and Modality." Philosophical Perspectives, 8, pp. 1-16.

. 1995a. "Senses of Essence." In Modality, Morality, and Belief: Essays in Honor of Ruth Barcan Marcus, ed. W. Sinnott-Armstrong, D. Raffmann, and N. Asher.

Cambridge University Press.

. 1995b. “The Logic of Essence." Journal of Philosophical Logic, 24, 3, pp. 241-273.

Fodor, J. 1993. "Review of José Luis Bermúdez, Thinking without Words." London Review of Books, 25, 19, pp. 16-17.

Herder, J. G. 2002. “Treatise on the Origin of Language." In his Philosophical Writings, trans. M. N. Forster. Cambridge University Press.

Kahneman, D., Slovic, P. and Tversky, A. 1982. Judgment under Uncertainty: Heuristics and Biases. Cambridge University Press.

Kant, I. 1998. Critique of Pure Reason. Trans. P. Guyer and A. Wood. Cambridge University Press.

Kern, A. 2006. Quellen des Wissens. Suhrkamp.

Moravcsik, J. M. E. 1994. "Essences, Powers, and Generic Propositions." In Unity, Identity, and Explanation in Aristotle's Metaphysics, ed. T. Scaltas, D. Charles, and M. L. Gill. Oxford University Press.

Nisbett, R. E. and Ross, L. 1980. Human Inference: Strategies and Shortcomings of Social 
Judgment. Prentice-Hall.

Porphyry. 2003. Introduction to Aristotle's Categories. Trans. J. Barnes. Oxford University Press.

Rödl, S. 2007. Self-Consciousness. Harvard University Press.

Stich. S. 1985. “Could Man Be an Irrational Animal?” Synthese, 64, 1, pp. 115-135.

Thompson, M. 2004. “Apprehending Human Form.” In Modern Moral Philosophy, ed. A. O’Hear. Cambridge University Press. 2008. Life and Action. Harvard University Press.

Tomasello, M. 1999. The Cultural Origins of Human Cognition. Harvard University Press.

Tomasello, M. and Call, J. 1997. Primate Cognition. Oxford University Press.

Wiggins, D. 2001. Sameness and Substance Renewed. Cambridge University Press. 